\title{
A STUDY OF SERUM NITROUS OXIDE IN HYPERTENSIVES AND NORMOTENSIVES OF KONASEEMA AREA OF EAST GODAVARI DISTRICT: A FUTURE MARKER OF HYPERTENSION?
}

\author{
Aditi Saha1 ${ }^{1}$ G.V.Benerji², Meka Farid Babu³ , D. Rekha4 ${ }^{4}$ Indira Banerjea ${ }^{5}$, Josna Jose ${ }^{6}$
}
1. Post Graduate Student, Department Of Biochemistry, Konaseema Institute Of Medical Sciences \& Research Foundation.
2. Professor, Department of Biochemistry, Konaseema Institute of Medical Sciences \& Research Foundation.
3. Assistant Professor, Department of Biochemistry, Konaseema Institute of Medical Sciences \& Research Foundation.
4. Assistant Professor, Department of Biochemistry, Konaseema Institute of Medical Sciences \& Research Foundation
5. Professor \& HOD, Department of Biochemistry, Konaseema Institute of Medical Sciences \& Research Foundation
6. Statistician, Department of Biochemistry, Konaseema Institute of Medical Sciences \& Research Foundation

\section{CORRESPONDING AUTHOR: \\ DR. ADITI SAHA \\ Room no. 209, Godavari Apartment, \\ NH 214, Chaitanya Nagar \\ Amalapuram, 533201 \\ E-mail: dr.anirbanbsmc@gmail.com}

\begin{abstract}
Essential hypertension is characterised by endothelial dysfunction and increased vascular tone and resistance. The former is the result of imbalance of endothelium derived contracting \& relaxing factors. Nitric oxide, which is produced locally by endothelium is crucial for maintaining vascular tone. It is still unclear whether NO is a marker or a mediator for endothelial dysfunction in hypertension and also whether changes in NO concentration occur as primary or secondary events. This study was conducted to study the role of nitric oxide in hypertensive cases and also find out the normal level of serum nitric oxide in this specific population of Konaseema area of East Godavari District of Andhra Pradesh. The present study was done in Department of Biochemistry, Konaseema Institute of Medical Sciences \& Research Foundation, Amalapuram, Andhra Pradesh. A total of 150 hypertensive and non diabetic patients aged between 30-72 years (M:F=1.5:1) was taken for the study. A total of 150 age and sex matched control were taken for comparison. Serum creatinine was measured and hypertensives having elevated serum creatinine $(>0.7 \mathrm{mg} / \mathrm{dl}$ ) were excluded from the study; this was done to rule out any effect of kidney functional status on level of serum nitric oxide. Serum nitrate was measured using colorimetric Griess assay. The data was analyzed using SAS 9.1 Software. The mean serum nitrate in hypertensive patients (43.77 \pm $0.29 \mu \mathrm{mol} / \mathrm{L})$ is higher than the controls $(38.57 \pm 5.02 \mu \mathrm{mol} / \mathrm{L})$ and is statistically significant. Elevated serum nitric oxide level in hypertensives indicates an endothelial cell response to the antihypertensive medications. Serum nitric oxide, thus may be used as a marker for predicting "future hypertensive"; this may allow the physicians to modulate life style of these "future hypertensive" before overt hypertension actually develops. Also, the mean serum nitrate in controls of this study is much different from the other studies; does it indicate that serum nitric oxide value is
\end{abstract}




\section{ORIGINAL ARTICLE}

population specific? Anyway, the authors feel that in order to establish both these points and comment with such conviction, much larger future studies are needed.

KEY WORDS: serum nitric oxide, essential hypertension, endothelial dysfunction, griess reaction.

INTRODUCTION: Hypertension is a condition that presently afflicts more than 1 billion people worldwide and is hence a leading cause of morbidity and mortality. Over time it has earned the euphemism "silent killer" as it is usually asymptomatic until the damaging effects are virtually observed. Hypertension is classified by etiology as being either primary or secondary. The pathophysiology of essential hypertension is still unclear ${ }^{1}$. Endothelium-dependent vasodilator

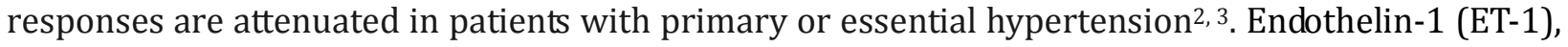
homocysteine (Hcy), and nitric oxide (NO) presently enjoys the focus of considerable attention in this regards $4,5,6,7$. However, the debate regarding their role in essential hypertension still goes on ${ }^{8,9}$. Hyperhomocysteinemia generates reactive oxygen species and reduces the bioavailability of NO via endothelial dysfunction ${ }^{10}$. Similarly, ET-1 has potent physiologic actions including vasoconstriction, cell proliferation, edema formation, and possibly a contribution to inflammation ${ }^{11,12}$. In addition, numerous studies have shown an interaction between ET- 1 and NO, a potent vasodilator, in the vascular endothelium ${ }^{13}$. Endothelium-dependent dilatation in resistance arteries is defective in patients with essential hypertension ${ }^{14}$. This dysfunction is a reflection of reduced bioactivity of N015. Hence, essential hypertension is characterised by endothelial dysfunction and increased vascular tone and resistance ${ }^{16}$. The former is the result of imbalance of endothelium derived contracting \& relaxing factors. Nitric oxide is produced locally by endothelium is crucial for maintaining vascular tone ${ }^{17}$; NO released from cells rapidly auto oxidizes to yield nitrite $\left(\mathrm{NO}^{2-}\right)$, which interacts with hemoglobin to yield nitrate ( $\mathrm{NO}^{3-}$ ). Because nitrite plus nitrate (nitrous oxide) is relatively stable in blood, the level of nitrate plus nitrite in blood may be an indicator of the endogenous formation of NO.

It is still unclear whether $\mathrm{NO}$ is a marker or a mediator for endothelial dysfunction in hypertension and also whether changes in NO concentration occur as primary or secondary events. Literature reveals many conflicting reports regarding the association between serum nitrous oxide and essential hypertension ${ }^{18}$.

The konaseema belt of East Godavari district of Andhra Pradesh, in development transition, has witnessed a marked increase in cardiovascular disease (CVD) morbidity and mortality. Nonetheless, little is known about the levels of circulating biomarkers in this population. We, therefore, aimed to carry out a case control study to evaluate plasma levels of nitric oxide (NO) among patients with essential hypertension and healthy normal control subjects (normotensive) in a heterogeneous sample population from this belt of Konaseema.

MATERIALS AND METHODS: This study was approved by Institutional Ethical Committee, Konaseema Institute of Medical Sciences and Research Foundation, Amalapuram. All subjects gave their written informed consent for participation. Blood pressure was measured conventionally by sphygmomanometer and the blood pressure of both groups was recorded. Resting BP measurements were performed in the sitting position between 8:00 AM and 10:00 AM on at least two separate days 1 week apart. Caffeinated beverages were avoided for at least $30 \mathrm{~min}$ prior to measurement. The recordings were made under quiet, comfortable ambient $\left(\sim 24^{\circ} \mathrm{C}\right)$ laboratory conditions. An appropriately sized cuff (cuff bladder encircling at least 80 percent of the arm) was used. Recordings 


\section{ORIGINAL ARTICLE}

were made in triplicate in the upright sitting position and the average recorded. Hypertensive cases were diagnosed as per the guidelines of JNC-7 (2003). Normal blood pressure was defined as systolic pressure $<140 \mathrm{~mm} \mathrm{Hg}$ and diastolic pressure $<90 \mathrm{~mm} \mathrm{Hg}$. Hypertension was defined as either systolic pressure $\geq 160 \mathrm{~mm} \mathrm{Hg}$ or diastolic pressure of $\geq 95 \mathrm{~mm} \mathrm{Hg}$, or both, with a well-documented history of long-term high blood pressure. 150 hypertensive Patients (30 years to 72 years; $\mathrm{M}: \mathrm{F}=1.5: 1$ ) not having other diseases like diabetes mellitus, renal disorder, cardiovascular disorders, cerebrovascular disorders etc. were included in the study. Cases and controls having serum creatinine more than $0.7 \mathrm{mg} / \mathrm{dl}$ were excluded from study. Causes of secondary hypertension, such as pheochromocytoma, renovascular disease, hyperthyroidism, and aortic coarctation were excluded in all patients by the primary physician on the basis of conventional clinical and laboratory criteria; pregnancy induced hypertension were not included in this study. The antihypertensive medications taken by the patients were documented and compared to note the influence of drugs on the serum nitrous oxide level. Total number of 150 age and sex matched persons, ranging from 31 years to 71 years with M: F ratio of 2:1, having normal blood pressure and no significant ailments were included in this study as controls. Participants were instructed to refrain from eating for 18 hours, drinking beverages containing alcohol or caffeine, or smoking for at least 24 hours before blood sampling.

Specimens $(1.5 \mathrm{~mL})$ of peripheral venous blood from the brachial vein were collected into heparinized tubes after the subjects had been sitting at rest for 15 minutes in a quiet room maintained at a temperature of $22^{\circ} \mathrm{C}$ to $24^{\circ} \mathrm{C}$. The blood was placed immediately in an ice bath and centrifuged within 30 seconds for 5 minutes at 2000g. $1 \mathrm{ml}$ of Glycine-NaOH buffer (pH=9.7), $1 \mathrm{ml}$ of protein free filtrate, $2 \mathrm{ml}$ of distilled water and 2-3 gms of $\mathrm{Cu}-\mathrm{Cd}$ granules were sequentially added in a tube; The tubes were placed on a rotor/shaker and mixed vigorously for 20-25 minutes; the $\mathrm{Cu}-\mathrm{Cd}$ granules reduced nitrate to nitrite. To $2 \mathrm{ml}$ of supernatant $1 \mathrm{ml}$ of Griess reagent A (consisting of $0.1 \%$ naphthyl ethylenediamine dihydrochloride in distilled water) was added. Then, $1 \mathrm{ml}$ of Griess Reagent - B (consisting of $1 \%$ sulfanilamide in $5 \% \mathrm{H}_{3} \mathrm{PO}_{4}$,) was added to the solution. The solution was incubated for 20 minutes and pink colour was observed. The absorbance was then read at 540 nm (19) to provide the total amount of plasma NO end products (nitrate plus nitrite). The efficiency of the cadmium column in the conversion of nitrate to nitrite was confirmed to be $100 \%$ by measuring both nitrate and nitrite standards before and after sample measurement ${ }^{19,} 20$.

STATISTICAL ANALYSIS: The data was analyzed using SAS 9.1 Software. Data was expressed as mean \pm SD. Standard deviation has been used to indicate whether the variation of difference of an individual from the mean is by chance. Independent T Test / Mann-Whitney U test was used based on the normality assumption to compare the groups. For Categorical variables, Chi-square/Fisher's exact test was used to compare the groups. Statistical analysis was performed applying independent sample $t$ test to the data of independent samples for equality of means between the groups and "Levenes Test for Equality of variances" within the group. The probability value of less than 0.05 was considered statistically significant because such a difference could commonly occur due to chance and the factors under study may have no influence on the variables.

Demographic characteristics of the subjects are summarized in table 1. Statistical analysis revealed that cases and controls were not significantly different with respect to their age (independent $\mathrm{t}$ test: $\mathrm{t}=0.77 ; \mathrm{P}=0.4404$ ) and sex (chi square test; $\mathrm{P}=0.2599$ ). 
Table 1: Demographic characteristics of the subjects:

\begin{tabular}{|l|l|l|l|}
\hline Characteristics & CASES (n=150) & CNTRL (n=150) & P VALUE \\
\hline Age & $53.98 \pm 10.98$ & $52.58 \pm 8.69$ & 0.4404 \\
\hline male & $90(60 \%)$ & $100(66.67 \%)$ & \multirow{2}{*}{0.2599} \\
\cline { 1 - 2 } female & $60(40 \%)$ & $50(33.33 \%)$ & \\
& & & \\
\hline
\end{tabular}

The respective values of systolic blood pressure, diastolic blood pressure and serum nitric oxide of both the groups are tabulated in table 2. Mann-Whitney $U$ test used based on the normality assumption to compare the two groups revealed that all the findings are significantly different among the two groups.

Table 2: Systolic blood pressure, diastolic blood pressure and serum nitric oxide of cases and controls.

\begin{tabular}{|l|l|l|l|l|}
\hline Characteristics & $\begin{array}{l}\text { CASES } \\
(\mathbf{n = 1 5 0 )}\end{array}$ & CNTRL (n=150) & Z Value & P VALUE \\
\hline SBP & $158.17 \pm 16.82$ & $116.00 \pm 7.24$ & 9.57 & $<0.0001$ \\
\hline DBP & $89.97 \pm 10.86$ & $71.50 \pm 9.36$ & 7.69 & $<0.0001$ \\
\hline NITRIC OXIDE & $43.77 \pm 0.29$ & $38.57 \pm 5.02$ & 3.70 & 0.0002 \\
\hline
\end{tabular}

The concentration of nitrous oxide (nitrate plus nitrite) in the plasma of systemic venous blood was significantly more in the hypertension group than in the control group. The plasma NITROUS OXIDE concentration showed a significant negative correlation with both systolic $(r=-0.22436, p=0.0138)$ and diastolic blood pressure $(r=-0.20502, p=0.0247)$. Also, the concentration of nitrous oxide did not show any significant differences between the groups taking different antihypertensive medications.

DISCUSSION: Hypertension can produce structural damage to aortic endothelial cells in animals, and pressure overload is associated with a direct toxic effect on human endothelium; impairment of the release of NO from vascular endothelial cells may thus contribute to the reduced plasma nitrous oxide concentrations in patients with essential hypertension. In a study of hypertension on serum Nitric Oxide (NO) and Vascular Endothelial Growth Factor (VEGF) concentrations in DOCA-Salt hypertensive ovariectomized rats, reduced serum NO and increased serum VEGF concentrations in hypertensive animals supported the concept of endothelial dysfunction in hypertensive subjects ${ }^{21}$. Besides its role as the most potent endogenous vasodilator, NO reduces the risk of heart disease by several mechanisms including decreased platelet aggregation, decreased low-density lipid oxidation, and decreased monocyte migration. 


\section{ORIGINAL ARTICLE}

The plasma concentration of nitrous oxide in systemic venous blood is determined by synthesis, degradation, and clearance of NO. As for the synthesis of NO, NO is continuously synthesized from Larginine in a reaction catalyzed by NO synthase. NO is produced from endothelial cells, leukocytes, platelets, nerves, cardiomyocytes, and muscles. In the present study, both cases and controls having elevated serum creatinine ( $>0.3 \mathrm{mg} / \mathrm{dl})$ was excluded from the study; hence, the serum nitrous oxide measured in both cases and controls reflects the endothelial status correctly. Daily activity and the consumption of food or water may also affect nitrous oxide concentration. This was taken care of by collection of blood samples only after 8 hours of fasting or 6 hours of abstaining from drinking.

Several reports are suggestive that hypertensive subjects have a blunted endothelium dependant vasodilatation which might be secondary to decreased nitric oxide production from the vessel wall 22, 23, 24. Further, reduced NO bioavailability is common in patients at high cardiovascular risk $^{25}$. Deterioration of endothelial function was observed in patients with hypertension with risk factors of atherosclerosis, especially coronary artery disease ${ }^{26}$. Both arterial hypertension and endothelial dysfunction plays a central role in development of atherosclerosis; biochemical evidences of marked endothelial dysfunction are present in hypertension in chronic renal failure ${ }^{27}$.

Endothelial dysfunction is indicated by decreased serum nitrate concentration as has been shown by various studies where essential hypertensive subjects were documented with endothelial dysfunction by the virtue of decreased serum nitrate values $28,29,30,31$. Hypertensive patients living in high mountains revealed low concentrations of nitric oxide metabolites in plasma, erythrocytes and blood which aggravated with progress of hypertension and its duration ${ }^{32}$.

There are two important points which the authors want to highlight through this study.

1). The normal serum $\mathrm{NO}(\mathrm{x})$ concentration, as was found in blood drawn from controls was $38.57 \pm 5.02 \mathrm{micromol} / \mathrm{L}$; this value is much different from the value obtained in other studies. In fact, the normal range of NO showed a wide variation in different studies 33, 34,35, 36, 37, 38,; hence, it necessitates working out the normal range of serum NO for a particular population. However, we stress that the reference value for NO in normal Indian subjects remains to be established.

2). Mean serum nitrate of hypertensive cases was higher than that of controls and is statistically significant ( $\mathrm{p}=0.0002)$; this is an adaptation of the blood vessel endothelium in response to antihypertensive medications; it may also reflect a protective mechanism against the action of vasoconstrictor compounds, including ET-139. Similar results have also been reported by Enyioma N et $\mathrm{al}^{39}$. Sainani et $\mathrm{al}^{40}$ revealed elevated levels of vasoconstrictors and reduced level of vasodilators in untreated essential hypertension subjects which confirmed the presence of endothelial dysfunction, even in mild cases of hypertension. They concluded that early detection of endothelial dysfunction may be a useful measure to guide therapy before the damaging effects of hypertension manifests.

In the present study, NO levels showed a significant difference between patients and controls. This suggests that an estimation of NO levels could be included as a routine lab investigation to screen people at risk and to devise appropriate individualized therapeutic strategies.

ACKNOWLEDGEMENT: The authors would like to thank Dr. Indira Banerjea, Professor and Head of the Department of Biochemistry, KIMS \& RF, Amalapuram for her valuable advice and guidance in giving the final shape to this manuscript.

\section{BIBLIOGRAPHY:}




\section{ORIGINAL ARTICLE}

1. Grassi G. Role of the sympathetic nervous system in human hypertension. J Hypertens.1998; 16: 1979-87.

2. Panza JA, Quyyumi AA, Callahan TS, Epstein SE. Abnormal endothelium-dependent vascular relaxation in patients with essential hypertension. N Engl J Med. 1990; 323: 22-27.

3. Linder L, Kiowski W, Buhler FR, Luscher TF. Indirect evidence for release of endotheliumderived relaxing factor in human forearm circulation in vivo: blunted response to essential hypertension. Circulation. 1990; 81: 1762-1767.

4. Treiber FA, Jackson RW, Davis H, Pollock JS, Kapuku G, Mensah GA, et al. Racial differences in endothelin- 1 at rest and in response to acute stress in adolescent males. Hypertension. 2000; 35: 722-5.

5. Nava E, Luscher TF. Endothelium-derived vasoactive factors in hypertension: Nitric oxide and endothelin. J Hypertens. 1995; 13: S39-48.

6. Schiffrin EL. Endothelin: Potential role in hypertension and vascular hypertrophy. Hypertension. 1995; 25: 1135-43.

7. Massy ZA, Ceballos I, Chadefaux-Vekemens B, Nguyen-Khoa T, Descamps-Latscha B, Drueke TB, et al. Homocyst(e)ine, oxidative stress, and endothelium function in uremic patients. Kidney Int Suppl. 2001; 78: 243-5.

8. Nava E, Luscher TF. Endothelium-derived vasoactive factors in hypertension: Nitric oxide and endothelin. J Hypertens. 1995; 13: S39-48.

9. Schiffrin EL. Endothelin: Potential role in hypertension and vascular hypertrophy. Hypertension. 1995; 25: 1135-43.

10. Massy ZA, Ceballos I, Chadefaux-Vekemens B, Nguyen-Khoa T, Descamps-Latscha B, Drueke $\mathrm{TB}$, et al. Homocyst(e)ine, oxidative stress, and endothelium function in uremic patients. Kidney Int Suppl. 2001; 78: 243-5.

11. Yanagisawa M, Kurihara H, Kimura S, Tomobe Y, Kobayashi M, Mitsui Y, et al. A novel potent vasoconstrictor peptide produced by vascular endothelial cells. Nature. 1986; 332: 411-5.

12. Haynes WG, Ferro CJ, O'Kane KP, Somerville D, Lomax CC, Webb DJ. Systemic endothelin receptor blockade decreases peripheral vascular resistance and blood pressure in humans. Circulation. 1996; 93: 1860-70.

13. Verhaar MC, Strachan FE, Newby DE, Cruden NL, Koomans HA, Rabelink TJ, et al. Endothelin-A receptor antagonist-mediated vasodilatation is attenuated by inhibition of nitric oxide synthesis and by endothelin-B receptor blockade. Circulation. 1998; 97: 752-6.

14. Falloon BJ, Heagerty AM. In vitro perfusion studies of human resistance artery function in essential hypertension. Hypertension. 1994; 24:16-23.

15. Panza JA, Casino PR, Kilcoyne CM, Quyyumi AA. Role of endothelium-derived nitric oxide in the abnormal endothelium-dependent vascular relaxation of patients with essential hypertension. Circulation. 1993; 87: 1468-1474.

16. Furchgott RF, Zawadzki JV. The obligatory role of endothelial cells in the relaxation of arterial smooth muscle by acetylcholine. Nature. 1980; 288: 373-376.

17. Vallance P, Collier J, Moncada S. Effects of endothelium-derived nitric oxide on peripheral arteriolar tone in man. Lancet. 1989; 2: 997-1000. 


\section{ORIGINAL ARTICLE}

18. Zhang SH, Ding JS, Jiao Y, Zhang Q, Peng H, Gao X, Xu YY, Zhang YH. Association between serum nitric oxide and hypertension among 1453 women in Suzhou. Zhonghua Liu Xing Bing Xue Za Zhi. 2011 Aug; 32(8): 760-3.

19. Moshage H, Kok B, Huizenga JR, Jansen PL. Nitrite and nitrate determination in plasma: a critical evaluation. Clin. Chem. 1995; 41:892-896.

20. Green LC, Wagner DA, Glogowski J, Skipper PL, Wishnok JS, Tannenbaum SR. Analysis of nitrate, nitrite and [15N] nitrate in biological fluids. Anal Biochem. 1982; 126:131-138.

21. Khazaei M, Nematbakhsh $M$. The effect of hypertension on serum nitric oxide and vascular endothelial growth factor concentrations. A study in DOCA-Salt hypertensive ovariectomized rats. Regul Pept. 2006 Jul 15; 135(1-2): 91-4.

22. Quyyumi AA, Dakak N, Mulcahy D, Andrews NP, Husain S, Panza JA, et al. Nitric oxide activity in the atherosclerotic human coronary circulation. J Am Coll Cardiol. 1997; 29: 30817.

23. Sarafidis PA, McFarlane SI, Bakris GL. Antihypertensive agents, insulin sensitivity, and newonset diabetes. Curr Diab Rep. 2007; 7: 191-9.

24. Jin L, Caldwell RB, Li-Masters T, Caldwell RW. Homocysteine induces endothelial dysfunction via inhibition of arginine transport. J Physiol Pharmacol. 2007; 58: 191-206.

25. Quyyumi AA, Dakak N, Mulcahy D, Andrews NP, Husain S, Panza JA, et al. Nitric oxide activity in the atherosclerotic human coronary circulation. J Am Coll Cardiol. 1997; 29: 30817.

26. Goch A, Banach M, Mikhailidis DP, Rysz J, Goch JH. Endothelial dysfunction in patients with noncomplicated and complicated hypertension. Clin Exp Hypertens. 2009 Feb; 31(1):20-30.

27. Cotton S, Mule G, Amato F. Amplified biochemical activation of endothelial function in hypertension associated with moderate to severe renal failure. J Nephrol. 2002 Dec; 15(6): 643-8.

28. Biljana Gerasimovska. Decreased Nitric Oxide in woman with essential hypertension in prehypertensive phase. Croat Med J. 2005; 40(6): 889-893.

29. Afrasyap L, Ozturk G. NO level and endothelial NO synthase gene polymorphism (Glu298Asp) in the patients with coronary artery disease from the Turkish population. Acta Biochemica Biophisica Sinica. 2004; 36(10), 661-666.

30. Kumar CA, Das UN. Lipid peroxides, antioxidants and nitric oxides in patients with preeclampsia and essential hypertension. Medical Science Monitor. 2000; 6: 901-907.

31. Node K, Kitakaze M, Yoshikawa H, Kosaka H, Hori M. Reduced plasma concentrations of NITROUS OXIDE in individuals with essential hypertension. Hypertension. 1997; 30: 405408.

32. Kurdanova MKH, Beslaneev IA, Batyrbekova LM, Berkhamova ZA, Sarbasheva AKH, Kurdanov KHA. The nitric oxide system in patients with arterial hypertension living in high mountains. Ter Arkh. 2007; 79(12): 25-8.

33. Ferlito S, Gallina M, Pitari GM, Bianchi A. Nitric oxide plasma levels in patients with chronic and acute cerebrovascular disorders. Panminerva medica. 1998; 40(1): 51-54.

34. Klahr S. The role of nitric oxide in hypertension and renal disease progression. Nephrology. Dialysis, Transplantation. 2001; 1 (16): 60-62. 


\section{ORIGINAL ARTICLE}

35. Kumar CA, Das UN. Lipid peroxides, antioxidants and nitric oxides in patients with preeclampsia and essential hypertension. Medical Science Monitor. 2000; 6: 901-907.

36. Jeerooburkhan N, Jones LC, Bujac S. Cooper JA, Miller GJ, Vallance P, Humphries SE, \& Hingorani AD. Genetic and environmental determinants of plasma nitric oxides and risk of ischemic heart disease. Hypertension. 2001. 38: 1054-1061

37. Ghasemi A, Zahedi Asl S, Mehrabi Y, Saadat N, Azizi F. Serum Nitric Oxide Metabolite Levels In A General Healthy Population: Relation To Sex And Age. Life Sci. 2008 Aug 29; 83(910):326-31.

38. Ghasemi A, Zahediasl S, Azizi F. Reference Values for Serum Nitric Oxide Metabolites In An Adult Population. Clin Biochem. 2010 Jan; 43(1-2): 89-94.

39. Enyioma N. Obineche, Abdishakur M.Abdulle, Javid Y Pathan and Nico J.D. Plasma Endothelin-1, Homocysteine, and Nitric Oxide Levels in a Multiethnic Hypertensive Cohort from the United Arab Emirates. Nagelkerke Journal of Medical Sciences. 2010; 3(3): 153159.

40. Sainani GS, Maru VG. Role of endothelial cell dysfunction in essential hypertension. J. Assoc Physicians India. 2004 Dec; 52: 966-99. 